\title{
Epigenetics, responsiveness and embodiment
}

\author{
Maria Kronfeldner \\ Central European University \\ (New York - Vienna - Budapest)
}

\begin{abstract}
Comment on Ch. Rehmann-Sutter “Developmental narratives: How we think that organisms use genetic and epigenetic information". In: "De-sequencing. Identity work with genes", ed. by D. Mahr and M. v. Arx. Palgrave Macmillan.
\end{abstract}

\author{
(C) Maria Kronfeldner, 2020. \\ Penultimate draft (preprint). \\ For the publisher's version, see: https://doi.org/10.1007/978-981-15-7728-4_5.
}

\section{Intro}

I want to comment on the connections Rehmann-Sutter (Ch 4, this volume) establishes between epigenetics, responsiveness and embodiment.

Epigenetics is hype and despite the limited evidence available, it has solidified a new conception of DNA as "responsive," and rightfully so. This new conception of DNA has gradually built up over the "century of the gene", to take Keller's (2000) phrase. Even though epigenetics is now a buzzword that is used in at least five senses (see Nicoglou and Merlin, 2017), I do not want to discuss the pros-and-cons of the different usages, since the differences do not matter much for the context at issue.

I will rather do the following: after introducing one such usage as a foundation for the discussion, I will discuss three issues that concern subsequent claims about epigenetics. I will come back to a different usage of the term 'epigenetics' (in particular a very broad usage of the term) at the very end of discussing the third issue. 
For the following, I will assume the meaning of epigenetics that Rehmann-Sutter suggests, which more or less is already present in the work of Jablonka and Lamb (2005). It includes, in contrast to other interpretations, "structural adaptations in certain chromosomal regions that change and co-determine the activity pattern of DNA" and "three-dimensional architectural patterns of cellular membrane systems, prions, or alternative self-sustaining, regulatory, metabolic feedback loops". The core of epigenetic processes is that they regulate gene action without changing the DNA. DNA is in that sense "responsive" to its epigenetic "regulators." Basically, the language of responsiveness and regulatory processes means that DNA can react to affordances that result from the interaction with the environment.

I will not discuss this characterization itself; I rather want to comment on three issues related to how it is used in Rehmann-Sutter's article, issues having to do with the ways in which epigenetics, responsiveness and embodiment are connected.

\section{Responsiveness as agency or causal process?}

First, we should be careful (hence the quotation marks in the above characterization of epigenetics) with any intentional, agency-suggesting language for molecular processes. It is either metaphorical language or it needs much more detailed justification of why it does not reduce to ordinary causal processes that - in the age of epigenetics - include processes of gene regulation.

Rehmann-Sutter is aware of the danger in such language when he distances himself from any claims about a cellular psyche or material consciousness and when he states that one needs to understand the change in meaning of the term 'response' if it is applied across the five "ontological levels involved in human embodiment". With respect to this layering of what "response" means at these different levels, he claims, for instance, that non-human animals and humans have different forms of subjectivity. Yet, given what he writes, I still wonder what the responsiveness of the first, the molecular "a-subjective" level amounts to, if not sheer causal interaction, as in any other causal process in the world? Certainly, these causal processes are "present in the context of other cells" but that presence is a far cry from the presence that enters a phenomenological "experience as lived body". 
Thus, the first issue I want to raise is the following: is there any difference between saying that there is an ongoing causal interaction of all kinds of developmental resources in parity (i.e. no causal primacy of one over the other) and saying that there is a "form of agency" at that first ontological level of human embodiment? I doubt it. Given that the history of talking about these things is, ever since Aristotle, laden with terms like 'agency', 'power' and the like, as stressed in particular by developmental systems theory, parsimony should be the guide in the way we talk about genetics, epigenetics and development.

\section{Epigenetics as reason for responsiveness at all levels?}

Rehmann-Sutter claims that epigenetics and its various theoretical interpretations "have important philosophical implications, because they significantly change the image that we have of our own embodiment. Embodiment, on all its ontological levels - from the molecules to cells to the developing organism - is a responsive process. Responsiveness does not appear only once the machinery of the body is completed, i.e. on the upper level of psychocorporeality. It is the organizing principle of all development." The conclusion - responsiveness is everywhere - is certainly correct (if we take, for the sake of the argument, the language to be neutral with respect to the first issue mentioned above). It even, one feels tempted to add, applies to evolution all the way down, if philosophers like Campbell (1974) or Dennett (1995) are correct, defending that there are basic processes of cognition very early in life (in Campbell's case) and "kinds of minds" (in Dennett's sense) equally early in life. Rehmann-Sutter also points to that evolutionary level when he mentions Jablonka's (2013) use of responsiveness. The problem is, however, that this then means that responsiveness in epigenetics is no big news. Responsiveness at the most basic ontological level is neither stemming from epigenetics, nor is it original or specific to epigenetics; it goes all the way down to the beginning of life. Rehmann-Sutter is aware of this when he writes that the lac operon model of gene regulation was already pointing to "systemic responsiveness" which is "therefore not restricted to epigenetic processes". Yet, if the latter is the case, then that is in tension with the above claim about the philosophical importance of epigenetics. 
Thus, the claim that should be defended with respect to responsiveness, taken all of the above into account, is that responsiveness (in the basic sense that can be defended even at the molecular level) is a property of life - whichever, i.e. a property of any life, be it life in our actual world with epigenetics or a life in a hypothetical (and maybe early world of evolution) without epigenetics. Epigenetics might further confirm that picture of overall responsiveness, but epigenetics is not the reason why there is responsiveness all the way down.

The specific philosophical importance of epigenetics is thus more limited. As Rehmann-Sutter mentions, it revises the so-called central dogma by allowing some reverse "information flow" and it turns Dawkins (1976) "selfish gene" picture upside-down: for Dawkins, DNA uses organisms; epigenetics entails that "organisms use their DNA". An exaggeration, since sometimes the epigenetics happens to the organism (e.g. via environmental stress) as the DNA happens to the organism, but an exaggeration that rightfully corrects another exaggeration. (One might go on by adding further specific issues for which epigenetics has been taken to be relevant - a frequently mentioned one is that it allegedly reintroduces Lamarckism -; but the point I want to make here is independent of any such list of specific implications.) Important here is that the claim that epigenetics puts the selfish-gene picture upside down is a much more specific claim than the claim that epigenetics shows that there is responsiveness all the way down to basic molecules.

As a matter of parsimony again, I think one should stick with specific claims or refer to the actual reason why there is responsiveness - namely, because we are talking about life.

\section{Embodiment already in nature-nurture interaction.}

Finally, because both Chapter 4 and the volume are about how identity and genes connect, be it via narratives or other ways of relating to one's lived body, I also want to raise some doubts about the tight connection Rehmann-Sutter makes between embodiment and epigenetics. Ever since nature versus nurture became an issue, embodiment has been an issue too. And nature versus nurture is a very old problem, going back at least to Greek antiquity and thus did not, as is often claimed, begin only in the $19^{\text {th }}$ century with Francis Galton (Kronfeldner 2018a). Certainly, any 
mind-body dualism is deciding the issue from the very start, entailing the irrelevance of nature (equated with the body). Yet, not all nature-nurture discussions were framed in a dualist mind-body ontology hypothesizing a mere body as distinct from a disembodied mind, and definitely not the ones in philosophy of biology, spearheaded by biologists like Richard Lewontin. In addition, there are those scientists, e.g. Caspi et al (2002), who show empirically that nature (in the context of their research: genetic and other innate factors) and nurture (which includes lived experience) interact in a strong sense - in a sense where it depends crucially on the environment in which the individuals live (abusive or not), as to which effect the respective genes have on the individual, e.g. increasing (one effect) or decreasing (another effect) the probability of aggressive behavior. If the data accumulated in this field are tracing causal processes - from an environment via individuals (with their bodies, including the brain) to the behavior of these individuals -, then these individuals literally embody the abusive or non-abusive environment (see Kronfeldner $2018 \mathrm{~b}$ for more on nature-nurture interacting). And these individuals will have quite some stories (i.e. narratives) to tell about that embodiment.

To the best of my knowledge, it is not yet clear whether the causal process that would account for the data accumulated by Caspi et al (2002) and others involves epigenetic processes, i.e. changes in gene regulation (for review see Tabery 2014). But it is clear, and independent of whether the process in fact involves epigenetics, that the gene-environment interaction at issue is a case of embodiment. It will still be a case of embodiment even if it turns out that it does not involve any changes in gene regulation.

One could certainly - by definitional fiat - say that epigenetics is even more inclusive than as introduced above, including all processes where an interaction of the body with an environment changes the "response" of the body (i.e. the behavior of the individual). Such a very broad concept of epigenetics (mentioned briefly when Rehmann-Sutter refers to Goldberg et al 2007) is close to useless since, on the basis of such a very broad concept, even the causal processes that account for why a plant grows taller when it receives more water would by definition be an epigenetic process since "the final outcome of a locus or chromosome" is changed "without changing the underlying DNA sequence." 
My third point is thus: the embodiment Rehmann-Sutter discusses is not dependent on epigenetics as long as epigenetics does not include everything, i.e. any geneenvironment interaction, which will include almost all processes of development (i.e. all those that do not follow a flat norm of reaction, since only in a flat norm of reaction, can the gene have the same effect irrespective of the environment the body lives in).

The risk in using a very broad concept of epigenetics (including almost everything as epigenetics) is that the discussion about development continues in a polarized manner: with a straw-man of genetic determination (i.e. a flat norm of reaction) put in opposition to a too broadly defined concept of epigenetics, with nothing inbetween.

\section{Summary}

Rehmann-Sutter points to important aspects of how genetics, epigenetics, responsiveness and embodiment are connected, as part of his account of developmental narratives. Yet, what he writes could be (mis-)read as still too laden with agency-talk and as mislocating the source for responsiveness and embodiment.

\section{REFERENCES}

Campbell, D. T. (1974) 'Evolutionary epistemology', in Radnitzky, G. and Bartley, W. W. (eds), Evolutionary epistemology: Rationality and the Sociology of Knowledge, LaSalle, IL, Open Court Publ., pp. 47-89.

Caspi, A., McClay, J., Moffitt, T. E., Mill, J., Martin, J., Craig, I. W., Taylor, A. and Poulton, R. (2002) 'Role of genotype in the cycle of violence in maltreated children', Science, vol. 297, pp. 851-854.

Dawkins, Richard. 1976. The Selfish Gene. Oxford: Oxford University Press.

Dennett, D. C. (1995) Darwin's dangerous idea: Evolution and the meanings of life, New York, Simon and Schuster.

Goldberg, A.D., Allis, C.D., Bernstein, E. (2007) Epigenetics: A landscape takes shape. Cell 128, pp. 635-638.

Jablonka, Eva, and Marion J. Lamb. 2005. Evolution in Four Dimensions: Genetic, Epigenetic, Behavioral and Symbolic Variation in the History of Life. Cambridge, MA: MIT Press.

Jablonka, E. (2013) Epigenetic inheritance and plasticity: The responsive germline. Progress in Biophysics and Molecular Biology 111, pp. 99-107. 
Keller, E. F. (2010) The mirage of a space between nature and nurture, Durham, NC, Duke University Press.

Kronfeldner, Maria. (2018a). “Divide and Conquer: The Authority of Nature and Why We Disagree about Human Nature." In Why We Disagree about Human Nature, edited by Elisabeth Hannon and Tim Lewens, 186-206. Oxford, Oxford University Press.

Kronfeldner, Maria. (2018b). What's Left of Human Nature? A Post-Essentialist, Pluralist, and Interactive Account of a Contested Concept. Cambrige, MA, MIT Press.

Nicoglou, Antonine, and Francesca Merlin. 2017. “Epigenetics: A Way to Bridge the Gap between Biological Fields." Studies in History and Philosophy of Science Part C: Studies in History and Philosophy of Biological and Biomedical Sciences 66 (December): 73-82.

Tabery, J. (2014) Beyond versus: The struggle to understand the interaction of nature and nurture, Cambridge, MA, MIT Press. 